\title{
PRETERIÇÃO DE PASSAGEIRO À LUZ DO CÓDIGO DE DEFESA DO CONSUMIDOR
}

\author{
Catharina Martinez Heinrich Ferrer ${ }^{1}$ \\ Jussara Suzi Assis Borges Nasser Ferreira ${ }^{2}$
}

\section{RESUMO}

$\mathrm{O}$ presente trabalho objetiva abordar tema recorrente na atualidade, tanto com relação à proteção ao consumidor, quanto às consequências jurídicas decorrentes do overbooking ou preterição de passageiros, prática adotada por algumas transportadoras aéreas e que consiste na venda ou reserva de lugares acima da capacidade máxima da aeronave. A matéria regulada de forma especifica pela ANAC e também pela legislação consumerista, resume tal prática, de forma adequada, como sendo falha na prestação de serviços. Assim, faz-se necessário o estudo acerca das obrigações da empresa aérea com relação aos passageiros prejudicados, bem como a apuração da responsabilização civil correspondente.

Palavras-Chave: Consumidores, Preterição, Falha, Obrigação, Responsabilização

\section{PASSENGER LIABILITY IN THE LIGHT OF THE CONSUMER PROTECTION CODE}

\begin{abstract}
This paper aims to address the current recurring theme, both with regard to consumer protection and the legal consequences of overbooking or passenger misconduct, a practice adopted by some airlines and consisting of the sale or reservation of seats above the maximum capacity of the airline. aircraft. The matter specifically regulated by ANAC and also by consumer legislation, summarizes such practice, adequately, as failure to provide services. Thus, it is necessary to study the obligations of the airline in relation to the passengers affected, as well as the determination of the corresponding civil responsibility.
\end{abstract}

Keywords: Consumers, Pretertainment, Failure, Obligation, Accountability

\section{INTRODUÇÃO}

O estudo tem por objeto enfrentar a questão recorrente da preterição de passageiros no setor dos transportes aéreos em razão da reiterada prática e repetição de casos concretos. Analisa-se a matéria consoante à defesa do consumidor, considerando a relação típica de consumo havida entre as empresas aéreas e passageiros. Assim, o responsável pela falha na prestação de serviços deve sofrer as sanções previstas no Código de Defesa do Consumidor, somadas àquelas previstas na legislação específica - Resolução no 400/2016 da ANAC -

\footnotetext{
${ }^{1}$ Mestranda em Direito pela Universidade de Marília - UNIMAR. Linha Empreendimentos Econômicos, Processualidade e Relações Jurídicas.

${ }^{2}$ Doutora em Direito das Relações Sociais pela Pontifícia Universidade Católica de São Paulo - PUC e Mestre em Direito pela Universidade Estadual de Londrina - UEL Advogada.
} 
conjugando o esforço legal para fins da melhor proteção dispensada ao passageiro preterido, determinando ao menos relocação ou ressarcimento, sem ser permitido relegar ao desamparo, aquele que vier a ter frustrada em sua expectativa legítima de locomoção por via aérea.

O overbooking se caracteriza pela sobrevenda de um serviço em maior quantidade do que a capacidade que a empresa pode fornecer, comumente ocorre no setor de transporte de passageiros e na hotelaria, resultando na não prestação do serviço pelo preço e forma pactuados. Neste binômio, reside a questão problema que a investigação enfrenta com o propósito de indicar percurso de composição, solução possível e adequada, mas registrando certa divergência em relação ao núcleo da questão, expressa pelo prejuízo decorrente de tal prática. Vale dizer que estudos apontam para o emprego de meios que, se adotados de forma correta, podem ser vantajosos para a empresa prestadora de serviços e para o consumidor, já que os preços das passagens seriam mais acessíveis em razão do esgotamento da lotação.

O tema tem por lastro seguro a metódica da constitucionalização do direito, enfocando o viés trazido pela pós-modernidade e as transformações daí decorrentes em sede dos contratos de transporte, em específico, os de transportes aéreos.

Em complemento, por indispensável, agrega-se à matéria a interpretação jurisprudencial dos tribunais pátrios, pelo relevo das contribuições trazidas com vistas à composição dos conflitos que prosperaram neste seguimento.

Por fim, para a obtenção dos resultados almejados, foram adotados os métodos sistêmico, analítico e finalístico.

\section{DIREITOS DO CONSUMIDOR NA PÓS-MODERNIDADE}

A defesa dos direitos do consumidor é obrigação do Estado, recepcionada como princípio de ordem pública e interesse social na Constituição Federal de 1988, consoante Art. $5^{\circ}$, inciso XXXII, e princípio da Ordem Econômica constante do elenco do Art. 170, inciso V. O Código de Defesa do Consumidor, Lei $\mathrm{n}^{\circ}$ 8.078/90, representou tutela singular ao dispor sobre a proteção do consumidor.

A centralidade das tutelas plurais em relação às questões sociais, significaram marco importante e destacado no direito brasileiro, promovendo ruptura paradigmática, reconhecida pelas transformações ocorridas na pós-modernidade, se descolando das tutelas individuais para alcançar a tutela coletiva dos direitos, construindo assim condições de possibilidade 
relevantes e necessárias ao direito que se espera eficaz, para dar respostas às complexidades próprias desta quadra temporal. Nesse sentido, Eduardo Bianca Bittar refere:

[...] o estado reflexivo da sociedade ante suas próprias mazelas, capaz de gerar um revisionismo completo de seu modus actuanti et faciendi, especialmente considerada a condição de superação do modelo moderno de organização de vida e da sociedade. Nem só de superação se entende viver a pós-modernidade, pois o revisionismo crítico importa em praticar a escavação dos erros do passado para a preparação de novas condições de vida. A pós-modernidade é menos um estado de coisas, exatamente porque ela é uma condição processante de um amadurecimento social, político, econômico e cultural, que haverá de alargar-se por muitas décadas até a sua consolidação. Ela não se encerra com a modernidade, pois, em verdade, inaugura uma mescla com os restos da modernidade (BITTAR, 2005, p. 108).

Essa superação seria parcial, pois não há o abandono das normas anteriores, e sim a sua revisão, como no caso do Código de Defesa do Consumidor, tido como uma norma pósmoderna "no sentido de rever conceitos antigos do Direito Privado, tais como o contrato, a responsabilidade civil e a prescrição" (TARTUCE; NEVES, 2014, p. 4-5).

Claudia Lima Marques também traz a ideia de pluralismo aos sujeitos pós-modernos, já que, além de proteger sujeitos, as normas tendem a tutelar outros valores, como os direitos humanos, cultura dos povos, meio ambiente (em que se relacionam), filosofia e tratamento diferenciado (MARQUES, 2004, p. 26).

Como consequência desse pluralismo e abundância dos gêneros e espécies, Flávio Tartuce e Daniel Amorim Assumpção Neves afirmam que há situações de colisão entre esses direitos, que seriam solucionadas com a interpretação da norma constitucional. Citam, inclusive, o exemplo de uma simples ida ao banco, em que temos a percepção de que a fila mais rápida é a prioritária, que atende pessoas em situações especiais. Nesse cenário, há o duplo sentido das coisas, "onde o certo pode ser o errado, e o errado pode ser o certo; o bem pode ser o mal, e o mal pode ser o bem [...]" (TARTUCE; NEVES, 2014, p. 7).

Dessa narrativa, extrai-se que o direito dos vulneráveis está sendo tutelado, mas não em detrimento do direito dos demais, que possuem plenas condições de aguardar na fila, obviamente, no limite permitido em lei para o caso das agências bancárias.

Antonio Junqueira de Azevedo, em continuidade ao pluralismo da pósmodernidade, traz a figura da hipercomplexidade da realidade, em que alguns casos que 
abordam a colisão de direitos fundamentais nas relações de consumo são analisados com profundidade para serem resolvidos (AZEVEDO, 2004, p. 26-27).

Alguns doutrinadores, como Ricardo Luis Lorenzetti, acreditam que esse período trouxe o caos contemporâneo, sendo que o Código de Defesa do Consumidor se enquadraria nesse conceito, por conter normas de Direito Privado e Direito Público, por encerrar conceitos indeterminados, representar uma norma aberta e encerrar a pauta mínima de proteção dos consumidores. (LORENZETTI Apud TARTUCE; NEVES, 2014, p. 9).

Resta claro, portanto, que a intenção do legislador ao expandir os direitos previstos na Constituição Federal, criando uma lei específica aos consumidores, foi realmente a de proteger seus interesses da melhor forma possível, tal pode ter causado alguns efeitos colaterais, como a pluralidade ou hipercomplexidade, mas nenhuma norma no Direito é absoluta, há a necessidade de interpretar a realidade fática, aplicando-se à problemática a tutela mais eficaz.

\section{CONTRATOS DE TRANSPORTE}

Os contratos de transporte estão definidos pelo artigo 730 do Código Civil Brasileiro, como sendo aqueles em que alguém se obriga, mediante remuneração, a transportar, de um lugar para outro, pessoas ou coisas (CÓDIGO CIVIL BRASILEIRO, 2002).

De acordo com Claudia Lima Marques:

[...] são sempre de consumo o transporte remunerado de pessoas ou de passageiros e suas bagagens. Este transporte terrestre, por ônibus, por carro e, menos frequentemente, por trem, pode firmar-se por escrito ou não, bastando a conduta do consumidor ao subir no transporte coletivo para formalizar o contrato, que se regulará geralmente por condições gerais afixadas ou não no coletivo. Já o transporte aéreo utiliza as chamadas "condições contratuais" anexadas ao bilhete, o mesmo ocorrendo com o transporte lacustre e marítimo, quando não existe um contrato de adesão por escrito. (MARQUES, 2014, p. 491).

É pacífico o entendimento de que a relação de transporte é de consumo e deverá ser interpretada pelo Código de Defesa do Consumidor em diálogo com o Código Civil Brasileiro, utilizando-se da legislação específica.

Com relação ao transporte aéreo o Superior Tribunal de Justiça decidiu, no AgRg no Resp 1.342.604/SP, rel. Min. Mauro Campbell Marques, 2. ${ }^{a}$ T., j. 03.06.2014, Dje 09.06.2014, 
que a responsabilidade civil das companhias aéreas em caso de má prestação de serviços é regulada pelo Código de Defesa do Consumidor.

Quanto ao transporte internacional, deve-se obedecer ao que estabelece o artigo 178 da Constituição Federal, modificado pela Emenda Constitucional no 7 de 1995, observando-se os acordos firmados pela União, atendido o princípio da reciprocidade (CONSTITUIÇÃO FEDERAL, 1988).

Claudia de Lima Marques, ainda, traz uma problemática acerca dos transportes aéreos, em que seria necessário analisar três pontos:

[...] 1) no nível constitucional, a hierarquia de direito fundamental do direito do consumidor e as mudanças no texto do art. 178 da CF/1988 cm a EC 7, de 1995; 2) no nível legal, o valor supralegal dos tratados de direitos humanos, e o valor de lei dos Tratados comerciais como os do sistema de Varsóvia e o valor do art. 732 do CC/2002; e 3) e se há possibilidade de diálogo entre estas fontes para observar as fontes nacionais e internacionais sob o princípio da Constituição de reparação integral de danos. (MARQUES, 2014, p. 499500).

A proteção ao consumidor possui expressa previsão na Constituição Federal, estabelecendo-se cláusula pétrea no ordenamento jurídico brasileiro e com direito à reparação integral pela responsabilidade objetiva em caso de dano. Nesse sentido, o artigo 178 de referido ditame legal sofreu alteração, a fim de adequar a realidade à norma e possibilitando, assim, um diálogo entre as fontes.

Nesse sentido, o diálogo das fontes no que tange à indenização por dano moral, “[ ...] por força do CDC, do CC/2002 e dos princípios constitucionais, por atraso, perda da conexão ou má prestação de serviços no transporte aéreo internacional, afastando a convenção de Varsóvia neste ponto, parece ser a melhor solução" (MARQUES, 2014, p. 501).

Por derradeiro, tem-se que os passageiros de transportes devem ser vistos como sujeitos de direitos fundamentais e consumidores, aplicando-se o Código de Defesa do Consumidor em conjunto com o Código Civil, observando, em contratos internacionais, as normas internacionais e princípios constitucionais, para benefício da parte mais frágil na relação.

3 OVERBOOKING E SUA PREVISÃO NA ANAC 
A preterição de passageiro, também conhecida como overbooking, possui previsão na Resolução $n^{\circ}$ 400, de 13 de dezembro de 2016, que dispõe sobre as condições gerais de transporte aéreo (ANAC, 2016).

A primeira abordagem consta na Seção II, sobre Atraso, Cancelamento do Serviço e Preterição, no sentido de que é obrigação do transportador informar ao passageiro, por meio veículos de comunicação disponíveis, por escrito, sobre o motivo do atraso, do cancelamento, da interrupção do serviço e da preterição, sempre que solicitado.

Nesse caso, o transportador também deverá oferecer as alternativas de reacomodação, reembolso e execução do serviço por outra modalidade de transporte, conforme dispõe o artigo 21 de referido texto legal. O artigo 22, por sua vez, traz uma conceituação acerca de preterição, que seria configurada quando o transportador deixar de transportar passageiro que se apresentou para embarque no voo originalmente contratado.

Já com relação ao voo que exceder a disponibilidade de assentos na aeronave, o transportador deverá procurar por passageiros voluntários para serem reacomodados em outro voo, sendo que essa reacomodação não será considerada preterição, e sim aceitação de compensação, conforme o artigo 23 da Resolução.

Havendo preterição, a resolução prevê que o transportador deverá efetuar imediatamente o pagamento de compensação financeira ao passageiro, por meio de transferência bancária, voucher ou em espécie, atendendo o que estabelece o artigo 24 nos casos de voo doméstico e internacional; prestar assistência material (artigo 26); e restituí-lo, de forma integral, se solicitado no aeroporto de origem, de escala ou conexão, sendo assegurado o retorno ao aeroporto de origem, ou proporcional ao trecho não utilizado, se o deslocamento já realizado aproveitar ao passageiro (artigo 30).

Por fim, o atendimento aos passageiros que sofrerem preterição e demais ocorrências, como atrasos, cancelamentos de voo e interrupção de serviço, deverá ser presencial no aeroporto, duas horas antes de cada decolagem e duas horas após cada pouso, permanecendo no local enquanto houver operação e necessidade (artigo 37).

Vertente que merece atenção, reside na revisão da reitera falha de serviço, ao sustentar que o overbooking poderia ser benéfico para as empresas de aviação e os usuários, desde que utilizado como uma estratégia geradora de bem-estar econômico líquido. Isto é, as aeronaves teriam aproveitamento próximo ao limite máximo, potencializando sua receita e 
permitindo que o custo por passageiro transportado seja reduzido, por meio de descontos em passagens aéreas (FERRAZ; OLIVEIRA, 2006).

O overbooking, como em sua forma e prática, chegou a gerar conflitos violentos e de proporções sérias, como divulgado recentemente, acerca de situação ocorrida com uma empresa aérea internacional, onde um passageiro foi agredido fisicamente por funcionário da companhia ao tentar retirá-lo do vôo. As reparações posteriores apenas minimizam o dano sofrido, mas permanece a afronta à dignidade da pessoa.

Por outro lado, conforme se demonstra a seguir, é pacífico na jurisprudência brasileira que a prática de overbooking caracteriza falha na prestação de serviços, utilizando as penalidades previstas no Código de Defesa do Consumidor, ressalvando-se, inclusive, o direito do usuário ser indenizado pelos danos sofridos.

\section{FALHA NA PRESTAÇÃO DE SERVIÇOS E AS CONSEQUÊNCIAS ESTABELECIDAS PELA LEGISLAÇÃO CONSUMERISTA}

O overbooking é reconhecido na jurisprudência como uma falha na prestação de serviços ao consumidor. Abordando o assunto, o STJ decidiu em AgRg no AREsp 409045 / RJ AGRAVO REGIMENTAL NO AGRAVO EM RECURSO ESPECIAL 2013/0341811-3, T3 - TERCEIRA TURMA, Relator Ministro João Otávio Noronha, julgado em 26/05/2015 que, após a entrada em vigor da Lei $n^{\circ}$ 8.078/90, a responsabilidade civil das companhias aéreas nesses casos não se subordina mais pela Convenção de Varsóvia ou pelo Código Brasileiro de Aeronáutica, mais sim ao Código de Defesa do Consumidor.

Para que a legislação consumerista seja aplicada avalia-se a existência de uma relação entre sujeitos jurídicos, substancialmente entre um sujeito ativo (fornecedor de produtos e prestador de serviços) e um sujeito passivo (consumidor); presente do poder do sujeito ativo sobre o objeto imediato, que seria a prestação, e sobre o objeto mediato da relação, que seria o bem jurídico tutelado; e, por fim, a evidência na prática de um fato ou acontecimento que gere consequências para o plano jurídico. (TARTUCE; NEVES, 2014. p. 67).

Verifica-se, nesse caso, a presença de todos os elementos necessários para a configuração da relação jurídica de consumo, quais sejam, o prestador de serviços e os consumidores (elementos subjetivos) e o serviço de transporte de passageiros (elemento objetivo). 
Nesse sentido, Flávio Tartuce e Daniel Amorim Assumpção esclarecem, nos termos do artigo 732 do Código Civil e do Enunciado 369 CJF/STJ, aprovado na IV Jornada de Direito Civil, que, em geral, são aplicáveis aos contratos de transporte, quando estes constituírem uma relação de consumo, as normas do Código de Defesa do Consumidor, desde que estas sejam mais benéficas aos consumidores, ora passageiros (TARTUCE, Flavio; ASSUMPÇÃO, Daniel Amorim, 2014, p. 109).

Superada qualquer dúvida a esse respeito, passa-se à exposição dos elementos da relação de consumo: a transportadora, termo utilizado pela ANAC para definir as empresas de voos comerciais ou particulares, é a fornecedora de serviços, cuja definição está expressa no caput do artigo $3^{\circ}$ do $\mathrm{CDC}$ :

Toda pessoa física ou jurídica, pública ou privada, nacional ou estrangeira, bem como os entes despersonalizados, que desenvolvem atividade de produção, montagem, criação, construção, transformação, importação, exportação, distribuição ou comercialização de produtos ou prestação de serviços. (CÓDIGO DE DEFESA DO CONSUMIDOR, 1990)

Por sua vez, os passageiros são os consumidores do serviço (deslocamento aéreo). Para melhor entender essa relação jurídica de consumo, Rizzato Nunes aponta que:

Temos dito que a definição de consumidor do CDC começa no individualismo, mais concreto (art. $2^{\circ}$, caput), e termina no geral, mais abstrato (art. 29). Isto porque, logicamente falando, o caput do art. $2^{\circ}$ aponta para aquele consumidor real eu adquire concretamente um produto ou um serviço, e o art. 29 indica o consumidor do tipo ideal, um ente abstrato, uma espécie de conceito difuso, na medida em que a norma fala da potencialidade, do consumidor que presumivelmente exista, ainda que possa não ser determinado. (NUNES, 2005, p. 72)

Verifica-se, portanto, que os usuários são efetivamente os destinatários finais do serviço, enquadrando-se, pois, na relação de consumo. Havendo falha nessa prestação, estamos diante de vícios de serviços, previstos no artigo 20 do Código de Defesa do Consumidor, com relação exclusivamente a sua qualidade, nos seguintes termos: "O fornecedor de serviços responde pelos vícios de qualidade que os tornem impróprios ao consumo ou lhes diminuam o valor, assim como por aqueles decorrentes da disparidade com as indicações constantes da oferta ou mensagem publicitária [...]" (CÓDIGO DE DEFESA DO CONSUMIDOR, 1990). 
O responsável, nesse caso, é o fornecedor, ou o prestador de serviço, resguardandose a solidariedade dos demais que indiretamente tenham participado da relação, nos termos dos artigos 34 e 25 , parágrafos $1^{\circ}$ e $2^{\circ}$.

Rizzato Nunes traz uma ideia do que seria um serviço prestado: “[...] é aquele feito de conformidade com a oferta e cujo desenvolvimento esteja adequado e do qual advenha resultado útil, da maneira prometida, e que se tenha estabelecido pelo prestador, quer ele o faça diretamente (como no exemplo do profissional liberar), quer se utilize de produto ou serviço de terceiros" (NUNES, 2005, p. 230). Qualquer serviço que se desvie de sua finalidade, de sua proposta ou oferta, é caracterizado como contendo vício.

Esse vício é tratado pela doutrina como de qualidade, aqueles “[...] impróprios ao consumo ou que lhes diminuam o valor, assim como aqueles decorrentes da disparidade com as indicações constantes da oferta ou mensagem publicitária” (NUNES, 2005. p. 233).

Claudia Lima Marques preconiza que a ideia de vício trazida pelo Código de Defesa do Consumidor facilita a satisfação do contratante e agiliza o processo de cobrança da prestação de serviço, onde “[...] a prestação de um serviço adequado passa a ser a regra, não bastando que o fornecedor tenha prestado o serviço com diligência.” (MARQUES, 2014, p. 1310).

Isso porque, conforme dito anteriormente, o serviço deve ser adequado e útil ao resultado a que se destina, conforme os termos da contratação havida pelo consumidor e o fornecedor de serviços. A autora ainda traça outros pontos relevantes acerca dessa temática:

[...] Enquanto o direito tradicional se concentra na ação do fornecedor do serviço, no seu fazer, exigindo somente diligência e cuidados ordinários, o sistema CDC, baseado na teoria da função social do contrato, concentra-se no efeito do contrato. O efeito do contrato é a prestação de uma obrigação de fazer, de meio ou de resultado. Este efeito, este serviço prestado, é que deve ser adequado para os fins que "razoavelmente deles se esperam"; é o serviço prestado, por exemplo, o transporte de passageiros, a pintura da parede de casa, a intervenção cirúrgica ou a guarda do automóvel na garagem, que deve possuir a adequação e a prestabilidade normal. Está claro que o fazer e seu resultado são inseparáveis, conexos de qualquer maneira, mas o CDC como que presume que o fazer foi falho, viciado, se o serviço dele resultante não é adequado ou não possui a prestabilidade regular. (MARQUES, 2014, p. 1310-1311).

Trata-se, portanto, de um inadimplemento contratual e, caso o prestador de serviços não solucione o problema, o consumidor poderá exigir, alternativamente e a sua escolha, 
conforme artigo 20 do CDC: "I - a reexecução dos serviços, sem custo adicional e quando cabível; II - a restituição imediata da quantia paga monetariamente atualizada, sem prejuízo de eventuais perdas e danos; III - o abatimento proporcional do preço." (CÓDIGO DE DEFESA DO CONSUMIDOR, 1990)

Fala-se ainda, em preterição de passageiros como vício de informação, já que o consumidor comprou a passagem acreditando que esta seria reservada e que poderia embarcar no dia e horário marcados. Esse vício é caracterizado pela disparidade entre as indicações constantes da oferta ou da mensagem publicitária e o serviço efetivamente prestado. (MARQUES, 2014, p. 1322).

A jurisprudência colaciona, analogicamente, decisões sobre o vício de informação e a responsabilização do prestador de serviços:

Direito do consumidor. Recurso especial. Ação de indenização por danos morais e materiais. Viagem ao exterior. Passageira bolivianaque adquiriu bilhete aéreo com destino à França e teve seu ingresso negado naquele país por não possuir visto consular. Fornecedor que não prestou informação adequada sobre a necessidade de obtenção do visto. Vício do serviço configurado. - De acordo com o $\S 2^{\circ}$ do art. 20 do CDC, consideram-se impróprios aqueles serviços que se mostram inadequados para os fins que razoavelmente deles se esperam. - A aferição daquilo que o consumidor razoalmente pode esperar de um serviço está intimamente ligada com a observância do direito do consumidor à informação, previsto no inciso III do art. $6^{\circ}$ do CDC. - Além de claras e precisas, as informações prestadas pelo fornecedor devem conter as advertências necessárias para alertar 0 consumidor a respeito dos riscos que, eventualmente, podem frustrar a utilização do serviço contratado. - Para além de constituir direito básico do consumidor, a correta prestação de informações revela-se, ainda, consectário da lealdade inerente à boa-fé objetiva e constitui o ponto de partida a partir do qual é possível determinar a perfeita coincidência entre o serviço oferecido e o efetivamente prestado. - Na hipótese, em que as consumidoras adquiriram passagens aéreas internacionais com o intuito de juntas conhecer a França, era necessário que a companhia aérea se manifestasse de forma escorreita acerca das medidas que deveriam ser tomadas pelas passageiras para viabilizar o sucesso da viagem, o que envolve desde as advertências quanto ao horário de comparecimento no balcão de "check-in" até mesmo o alerta em relação à necessidade de obtenção do visto. - Verificada a negligência da recorrida em fornecer as informações necessárias para as recorrentes, impõe-se o reconhecimento de vício de serviço e se mostra devida a fixação de compensação pelos danos morais sofridos. Recurso especial provido para condenar a recorrida a pagar às recorrentes $R \$$ $20.000,00$ (vinte mil reais) a título de compensação por danos morais. Ônus sucumbenciais redistribuídos. (REsp 988.595/SP, rel. Min. Nancy Andrighi, 3. ${ }^{\mathrm{T} T}$., j. 19.11.2009, DJe 09.12.2009) 
As opções que o consumidor possui são as mesmas tanto no vício de qualidade quanto no vício de informação e, a responsabilização pode alcançar todos os envolvidos na prestação de serviços, já que se fala em solidariedade passiva. Para encerrar as características do vício de qualidade, faz-se necessário dizer que a ignorância do fornecedor não o exime de responsabilidade, conforme o artigo 23 do Código de Defesa do Consumidor.

Os prazos para reclamação dos vícios são decadenciais e devem obedecer as diretrizes do artigo 26 do Código de Defesa do Consumidor, sendo "[...] de trinta dias, no caso de serviços não duráveis, e de noventa dias para os serviços duráveis. Tais prazos serão contados da execução do serviço (vício aparente) ou de seu conhecimento (vício oculto). (TARTUCE; NEVES, 2014, p. 168-169).

$\mathrm{Na}$ preterição de passageiros, constata-se essencialmente o vício na qualidade, haja vista que o serviço foi ofertado e, no momento de embarque, os passageiros descobrem que a empresa aérea vendeu bilhetes acima da capacidade máxima do avião.

Assim, com relação à falha dos serviços, a ementa trazida pelo TJRJ - APELAÇÃO APL 00153891320118190203 RJ 0015389-13.2011.8.19.0203 (TJ-RJ) - Publicado em 08/04/2014, aborda a problemática:

APELAÇÃO CÍVEL. TRANSPORTE TERRESTRE. PRÁTICA DE OVERBOOKING. CÓDIGO DE DEFESA DO CONSUMIDOR TEORIA DO RISCO DO EMPREENDIMENTO. DANOS MATERIAIS E MORAIS. OCORRÊNCIA. QUANTUM DEBEATUR. REDUÇÃO. 1. O caso em tela versa sobre relação de consumo, pois os autores enquadram-se no conceito de consumidor descrito no artigo $2^{\circ}$ do Código de Proteçâo e Defesa do Consumidor e a ré no de fornecedora, nos termos do artigo $3^{\circ}$ do mesmo diploma legal. É que os demandantes são os destinatários finais dos serviços ofertados pela demandada. 2. Da leitura do art. 14 do CPDC, verifica-se que a responsabilidade do fornecedor de serviços é objetiva e somente não responderá pela reparação dos danos causados ao consumidor se provar que, tendo prestado o serviço, o defeito inexiste ou o fato é exclusivo do consumidor ou de terceiro. 3. Na espécie, a falha na prestação do serviço está evidenciada na venda de duas passagens para a mesma poltrona, ocorrendo o chamado overbooking, além da falta de informação e assistência material adequada. 4. Dano moral in re ipsa. Indenização reduzida ao valor de $\mathrm{R} \$ 1.000,00$ (mil reais), em observância ao critério de proporcionalidade e circunstâncias do caso concreto. 5. Parcial provimento a recurso.

A responsabilização da empresa fornecedora também encontra precedentes, como, por exemplo, na ementa do TJSP - Apelação APL 212405320078260114 SP 0021240- 
53.2007.8.26.0114 (TJ-SP), aduzindo que a venda de passagem aérea sem que exista o respectivo assento na aeronave gera dano material in re ipsa (aquele que é presumido, não depende de comprovação), já que atenta contra a dignidade e a segurança da pessoa. Com relação ao dano moral, este deve ser suficiente para compensar o abalo moral sofrido pela vítima, bem como para punir e inibir a reincidência da conduta lesiva do ofensor, analisandose cada caso em particular.

Nesse sentido, o posicionamento do STJ, no AgRg no AREsp 737635 / PE AGRAVO REGIMENTAL NO AGRAVO EM RECURSO ESPECIAL 2015/0160713-0, Terceira Câmara, Relator Ministro João Otávio de Noronha, julgado em 27/10/2015:

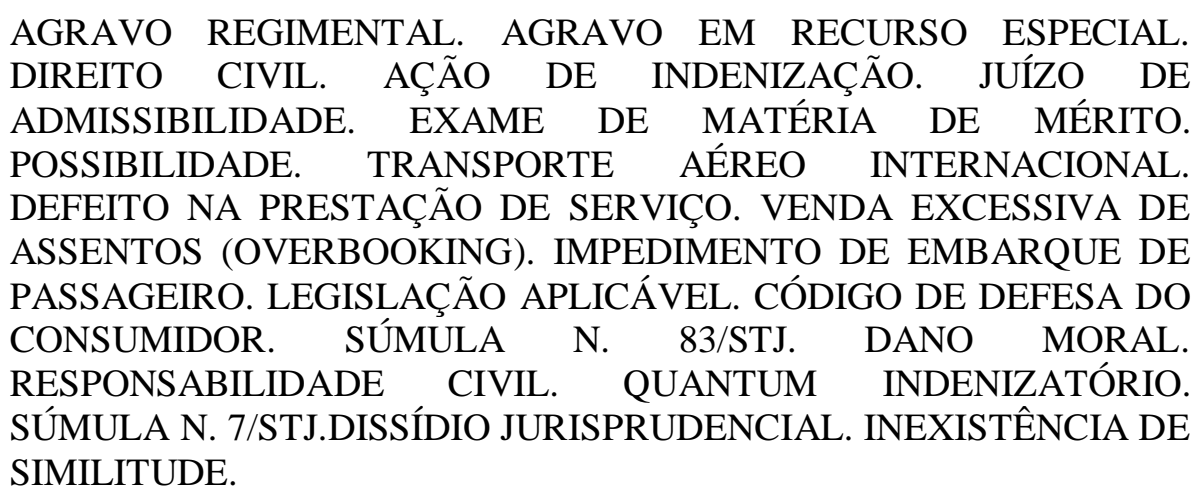

Importante dizer que a preterição de passageiros, além de configurar uma falha na prestação de serviços, também indica uma prática abusiva por parte das empresas de transporte aéreo, vedada pelo Código de Defesa do Consumidor, em seu artigo 6º inciso IV.

Essa ideia de abusividade, de acordo com a doutrina, diz respeito à "[...] constatação de que o titular de um direito subjetivo pode dele abusar no seu exercício que acabou por levar o legislador a tipificar certas ações como abusivas” (NUNES, Rizzato, 2005, p. 131).

O abuso de direito, portanto, significa o uso irregular do direito por parte de seu titular, durante o exercício deste, e possui um rol explicativo na legislação consumerista, em seus artigos 39, 40, 41, 42 etc.

Há claramente uma ofensa a outros princípios, quais sejam, da dignidade da pessoa humana, transparência, boa-fé, igualdade nas contratações, dever de informar, proteção contra a publicidade enganosa ou abusiva; e prevenção e reparação de danos materiais e morais. Razão pela qual o Código de Defesa do Consumidor se mostra tão necessário para tutelar as relações tidas como de consumo, como a do presente caso, em que a empresa, objetivando apenas o seu lucro, acaba por prejudicar tantos passageiros, que são surpreendidos com a 
informação de que o bilhete que haviam comprado com antecedência, na verdade, não possui lugar físico no avião.

O Código de Defesa do Consumidor, baseia-se, ainda, no Princípio da Reparação Integral dos Danos, em que: “[...] o regramento fundamental é a reparação integral dos danos, que assegura aos consumidores as efetivas prevenção e reparação de todos os danos suportados, sejam eles materiais ou morais, individuais, coletivos ou difusos." (TARTUCE; NEVES, 2014, p. 55). Outro princípio observado é o da segurança, que gera aos prestadores e fornecedores de serviços a responsabilização objetiva, afastando-se a necessidade de prova do elemento culpa.

Assim, a responsabilização dessas empresas por toda essa prática abusiva deve ser efetiva, assegurando aos consumidores uma prestação jurisdicional do Estado, para terem seus prejuízos ressarcidos, tanto no âmbito material quanto no moral, caso haja.

\section{CONCLUSÃO}

A preterição de passageiros é uma prática recorrente nas empresas aéreas, tanto que foi a ANAC regulamentou a matéria, objetivando a proteção do consumidor, tratando sobre as causas e alternativas a esse problema, como reacomodação ou até mesmo devolução do valor gasto.

Ocorre que, tais práticas, além de constituírem uma ofensa ao consumidor desacata o Código de Defesa do Consumidor e todos os princípios nele contidos, sendo prática abusiva, plenamente indenizável. Ademais, o dano material, conforme visto na jurisprudência colacionada, é in re ipsa, ou seja, não depende de comprovação. Já o dano moral carece de ser analisado em cada caso concreto, sendo diferenciado de meros aborrecimentos da vida cotidiana para obrigar a empresa área a ressarcir os consumidores que sofreram esse abalo emocional.

A proteção constitucional consumidor, tratada de forma específica pela legislação nacional infraconstitucional, assegura seus direitos reconhecidos como obrigação do Estado, sua manutenção e preservação, por ser a parte mais frágil da relação. O que se pretende não é o favorecimento de determinado grupo de pessoas, mas sim a sua defesa, já que per si não teriam condições de fazê-la. 
O Código de Defesa do Consumidor surge como um marco para o Direito Brasileiro, promovendo ruptura de paradigmas em relação à clássica proteção do tutela individual para alcançar a tutela coletiva dos direitos, somando-se o diálogo das fontes, suprindo qualquer nulidade ou obscuridade, em benefício do consumidor, do cidadão comum, desses passageiros de transporte, seja terrestre ou aéreo.

A abordagem do contrato de transporte, com sua conceituação e regulação e, especificamente com relação ao aéreo, remarca como incontroverso o fato de que tanto no âmbito nacional quanto internacional, qualquer prática das empresas que não corresponda com o serviço contratado deve ser coibida.

No contexto da relação de consumo sob estudo, restou evidente, com a presença de todos os elementos de sua caracterização, tais como o prestador de serviços e o consumidor (elemento subjetivo) e prestação de serviços (elemento objeto), a indiscutível relação de consumo consubstanciada no caso transporte aéreo.

Assim, mesmo diante de posições contrárias acerca do Código de Defesa do Consumidor, relatando, inclusive, alguns efeitos colaterais, como a pluralidade de sujeitos ou a sua complexibilidade, não seria possível sanar o problema da preterição de passageiros com outra legislação, somada à Resolução da ANAC.

É papel do Estado, de qualquer outra entidade e, principalmente, de qualquer pessoa comum, que esteja diante de uma situação como esta, que efetivamente façam ser respeitadas as diretrizes traçadas pela legislação pertinente resguardando-se, em específico, a boa-fé contratual, a dignidade da pessoa humana e a proibição de práticas tidas como abusivas em sede de falha de serviço no transporte aéreo. Afinal, essa abusividade pode aparecer na reiteração dos atos, caso as empresas aéreas e demais prestadoras de serviços não sejam punidas por seus atos.

Solução importante apresentada para o enfrentamento do problema, surge representada pela ponderação de que o overbooking apresenta possibilidade de vantagens e benefícios para empresas aéreas e passageiros ao ser utilizado como uma estratégia geradora de bem-estar econômico. Para tanto, as empresas devem fazer o aproveitamento das aeronaves, respeitando o limite máximo e, de outra parte, reduzindo os custos por passageiros por meio de descontos em passagens aéreas, ofertadas em outros horários de menor fluxo, potencializando receita, permitindo que o custo por passageiro transportado seja reduzido e eliminando a recorrente falha de serviço, neste seguimento. 
O Direito está em constante evolução e não seria diferente nessa temática, sendo imprescindível a busca constante e permanente para a eficácia do direito a concretização da justiça e, sobretudo, que as relações jurídicas relativas às partes débeis sejam protegidas.

\section{REFERÊNCIAS}

AgRg no Resp 1.342.604/SP, rel. Min. Mauro Campbell Marques, 2. ${ }^{a}$ T., j. 03.06.2014, Dje 09.06.2014. Disponível

em: http://www.stj.jus.br/SCON/jurisprudencia/toc.jsp?livre=overbooking\&\&b=ACOR\&thesauru $\mathrm{s}=\mathrm{JURIDICO \& p=true.} \mathrm{Acesso} \mathrm{em:} 05$ de maio de 2017.

AgRg no AREsp 409045 / RJ AGRAVO REGIMENTAL NO AGRAVO EM RECURSO ESPECIAL 2013/0341811-3, T3 - TERCEIRA TURMA, Relator Ministro João Otávio Noronha, julgado em 26/05/2015. Disponível em: http://www.stj.jus.br/SCON/jurisprudencia/toc.jsp?livre=overbooking\&\&b=ACOR\&thesauru $\mathrm{s}=J U R I D I C O \& p=$ true. Acesso em: 05 de maio de 2017.

AZEVEDO, Antonio Junqueira de. Parecer. O direito como sistema complexo e de $\mathbf{2}^{\mathbf{a}}$ ordem; sua autonomia. Ato nulo e ato ilícito. Diferença de espírito entre responsabilidade civil e penal. Necessidade de prejuízo para haver direito a indenização na responsabilidade civil. Estudos e pareceres de direito privado. São Paulo: Saraiva, 2004. p. 26-27.

BITTAR, Eduardo C. B. O direito na pós-modernidade. Rio de Janeiro: Forense Universitária, 2005. P. 97-100.

CÓDIGO CIVIL BRASILEIRO, 2002. Disponível em: http://www.planalto.gov.br/ccivil_03/LEIS/2002/L10406.htm. Acesso em: 08 de maio de 2017.

CÓDIGO DE DEFESA DO CONSUMIDOR, 1990. Disponível em: http://www.planalto.gov.br/ccivil_03/LEIS/L8078.htm. Acesso em: 08 de maio de 2017.

CONSTITUIÇÃO FEDERAL BRASILEIRA, 1988. Disponível em: http://www.planalto.gov.br/ccivil_03/Constituicao/Constituicao.htm. Acesso em: 08 de maio de 2017.

ENUNCIADO 369 CJF/STJ. Disponível em: http://daleth.cjf.jus.br/revista/enunciados/IVJornada.pdf. Acesso em 07 de maio de 2017.

FERRAZ, Renée Baptista; OLIVEIRA, Alessandro Vinicíus Marques de. A Estratégia de Overbooking e sua Aplicação no Mercado de Transporte Aéreo Brasileiro. Disponível em:

https://edisciplinas.usp.br/pluginfile.php/212895/mod_resource/content/1/Texto\%20Overboo king.pdf. Acesso em: 03 de maio de 2017. 
MARQUES, Claudia Lima. Contratos no Código de Defesa do Consumidor: O novo regime das relações contratuais. 7. ${ }^{\text {e }}$ ed. São Paulo: Revista dos Tribunais, 2014.

MARQUES, Claudia Lima. Comentários ao Código de Defesa do Consumidor. São Paulo: Revista dos Tribunais, 2004, p. 26.

NUNES, Rizzatto. Curso de Direito do Consumidor. 2ª ed. São Paulo: Saraiva, 2005.

RESOLUÇÃO No 400, DE 13 DE DEZEMBRO DE 2016 DA ANAC (AGÊNCIA NACIONA̧L DE AVIAÇÃO CIVIL). Disponível em: http://www.anac.gov.br/assuntos/legislacao/legislacao-1/resolucoes/resolucoes2016/resolucao-no-400-13-12-2016/@ @display-file/arquivo_norma/RA2016-0400.pdf. Acesso em: 27 de abril de 2017.

REsp 988.595/SP, rel. Min. Nancy Ahdrighi, 3. ${ }^{\mathrm{a}}$ T., j. 19.11.2009, DJe 09.12.2009. Disponível http://www.stj.jus.br/SCON/jurisprudencia/toc.jsp?processo=988595\&\&b=ACOR\&thesaurus $=$ JURIDICO\&p=true. Acesso em: 13 de maio de 2017.

TARTUCE, Flavio; NEVES, Daniel Amorim Assumpção. Manual de Direito do Consumidor: Direito Material e Processual. Volume Único. São Paulo: Editora Método, 2014.

TJRJ - APELAÇÃO APL 00153891320118190203 RJ 0015389-13.2011.8.19.0203 (TJRJ) - $\quad$ Publicado em 08/04/2014. Disponível em: https://www.jusbrasil.com.br/jurisprudencia/busca?q=Overbooking.+C\%C3\%B3digo+de+De fes. Acesso em: 05 de maio de 2017.

TJSP - Apelação APL 212405320078260114 SP 0021240-53.2007.8.26.0114 (TJ-SP). Disponível em: https://www.jusbrasil.com.br/jurisprudencia/busca?q=Overbooking.+C\%C3\%B3digo+de+De fes. Acesso em: 05 de maio de 2017. 